block of wood with lapidary's cement; Nicol's process was essentially to substitute glass for wood and Canada balsam for the cement.

Nicol's collection in the British Museum (Natural History) contains, in addition to petrified plants, a few sections of flint and other pebbles, as well as of coal, cannel and lignite. Alexander Bryson's largely contemporary collection, also in the British Museum, includes sections of various minerals and rocks, and of corals and other fossil animals. There are incidental references to thin slices of minerals in some of Brewster's papers, and the technique had evidently been employed in Edinburgh on a wide range of minerals, rocks and fossils for many years before Sorby came on the scene, even if its applications were not pursued very far, except in the case of petrified plants.

Sorby's 1851 paper dealt with certain sedimentary rocks ; but W. C. Williamson, from whom Sorby learnt the technique of preparing thin sections, had already in his classic memoir on "Microscopic Objects in the Mud of the Levant" (1848) ${ }^{3}$ examined "thin sections of oolitic limestones from Bristol, Durdham Down, Yorkshire and Skerry". Williamson's interests were primarily biological; but his pioneering efforts are worthy of remembrance in any account of the early history of the microscopic study of rocks.

Department of Geology,

W. N. EDWARDS

Britigh Museum (Natural History), London, S.W.7.

${ }^{1}$ Nature, 168, 98 (1951).

${ }^{2}$ Edin. New Phil. J., 16, 157 (1834).

${ }^{3}$ Mem. Manchester Lit. Phil. Soc., (2), 8, 99 (1848).

MY article on Nicol and Sorby was intended to direct attention to two centenaries of especial interest in the history of microscopic petrography, that is, the examination of thin sections of rocks, which are, in most cases, mineral aggregates. It is generally recognized that the initial impetus to the development of this most important branch of geology was given by Sorby in the papers to which reference is made in my article; and also that the polarizing prism invented by Nicol and used by Sorby played an essential part in the development of the new science.

Nicol's statement, quoted by Mr. Edwards, certainly shows that he had made thin sections of minerals, but so had other and earlier workers. Prof. W. T. Gordon gave a short account of the history of the examination of stony material by means of thin sections to the British Association in $1926^{1}$. He mentioned there that Brewster made slices of amethyst one-fiftieth of an inch thick as early as 1817. In fact, Brewster made use of thin slices or plates of minerals for his optical studies several years earlier ${ }^{2}$.

I am indebted to Mr. Edwards for directing my attention to the paper published by W. C. Williamson in 1848 in which he refers to examining thin sections of oolitic limestone from several localities. William. son's paper was read in November 1845, and it is worth noting that in August of the same year John Phillips read a paper to a Yorkshire society in which he also refers to the examination of calcareous rocks in transparent sections ${ }^{3}$ (a fact unknown to me when I prepared my article). It therefore seems that the advantages of this technique were becoming known in the eighteen-forties, especially in northern England.
That many of the sections made by Nicol and Bryson are preserved in the British Museum (Natural History) has escaped the notice of previous writers on Nicol, and indeed seems to have been unknown even to C. D. Sherborn, in his "Where is the Collection ?" (Cambridge, 1940). Sherborn noted only that the Nicol and Bryson collections were sold in 1868 , and not that they were acquired by the British Museum. An account of these and any similar collections would be useful and interesting, and might provide a clue to the relative priority of Sorby, Williamson, Phillips, and possibly others in this field.

20 Trebovir Road,

London, S.W.5.

'Gordon, W. T., "The Preparation of Thin Sections (History)" Rep. Brit. A'ssoc., Oxford, 1926, 348 (London, 1926).

${ }^{2}$ Brewster, D., Phil. Trans., 104, Pt. 1, 187 (1814).

${ }^{3}$ Phillips, J., "On the Remains of Microscopic Animals in the Rocks shire (Leeds, 1846) (author's separate).

\section{Could an Arms-Race End Without Fighting?}

THERE have been only three great arms-races. The first two of them ended in wars in 1914 and 1939 ; the third is still going on. From so few events we cannot hope to draw any reliable conclusions by statistics. Let us instead see whether an analysis of motives throws any light on the problem. Arms, in peace-time, are intended to overawe possible enemies; therefore the motive of submission must come into the picture. Arms, in peace-time, in fact provoke possible enemies to prepare to defend themselves ; so defensiveness must be taken into account. There is also considerable grumbling about the cost of rearmament. The behaviour of large groups of people is more regular and less capricious than the behaviour of individuals. It is instructive to regard large groups as deterministic, and to represent their behaviour by differential equations, provided that we remember that such a treatment is a caricature. The following simultaneous pair of equations were published $^{1}$ for that purpose in 1939.

$$
\begin{aligned}
& \mathrm{d} x / \mathrm{d} t=k y\{1-\sigma(y-x)\}-\alpha x+g, \\
& \mathrm{~d} y / \mathrm{d} t=l x\{1-\rho(x-y)\}-\beta y+h .
\end{aligned}
$$

Here $t$ is time, $x$ and $y$ are the war-like preparations of the opposing sides, and the other letters are constants. Of these, $k$ and $l$ are positive 'defence coefficients', $\sigma$ and $\rho$ are positive measures of 'submissiveness', $\alpha$ and $\beta$ are positive measures of the objection to the cost of rearmament; but $g$ and $h$, which represent feelings, not about arms but about the treaty-situation, may have either sign. The names of the opposing nations do not appear, because the motives are supposed to be common to mankind ; but the numerical values of the constants may differ from nation to nation.

The validity of these equations was reconsidered in more detail, and by comparison with more historical evidence, in a microfilm ${ }^{2}$ published in 1947. The equations were found to be a tolerably good representation of what had happened. Better measures of $x$ and $y$ were introduced under the name of 'warfinpersal', which means the annual 'defence' expenditure divided by the annual earnings of a semiskilled engineer. By the time that an arms-race had grown to alarming proportions, it was found to be difficult to distinguish the effects of $\alpha, \beta, g$ or $h$, 